\title{
Biodiesel Production by Methanolysis of Soybean Oil over Sro Loaded Coal Fly Ash
}

\author{
Stuti Katara, Deepak Karsolia and Ashu Rani* \\ Department of Pure \& Applied Chemistry, University of Kota, India
}

Submission: October 30, 2017; Published: March 19, 2018

*Corresponding author: Ashu Rani, Department of Pure \& Applied Chemistry, University of Kota, 2-M-1, Rangbari scheme, Kota-324005, Rajasthan, India, Tel: +91 9352619059; Email: ashu.uok@gmail.com

\section{Abstract}

Coal fly ash is converted into an efficient solid base catalyst by suitable mechanical and thermal activation followed by deposition of 15 $w t \%$ strontium carbonate to generate catalytic active sites. The activity of the catalyst was tested for biodiesel production by soybean oil methanolysis (transesterification). The physico-chemical properties of catalyst were investigated by $\mathrm{N}_{2}$ adsorption-desorption study, FTIR and SEM analytical techniques. The catalyst could be easily regenerated and reused up to three reaction cycles with almost similar efficiency.

Keywords: Fly ash; Transesterification; Biodiesel

\section{Introduction}

Base catalysis is an important area of fundamental industrial importance in fine chemical, petrochemical, agrochemical and pharmaceutical industries. Commercially the base catalyzed reactions are largely carried out by using homogeneous bases like $\mathrm{NaOH}, \mathrm{Ca}(\mathrm{OH})_{2}$, $\mathrm{KOH}$ etc. [1]. Transesterification of triglycerides catalyzed by both acid and base has been reported. Base catalyst is more effective than acidic because in acidic condition there is more possibility to form undesired product which decreases the conversion of biodiesel. But in case of homogeneous catalysis it is far difficult to separate catalyst from reaction mixture and their reuse, regeneration are not possible generally and also have an extra step to separate, therefore the cost of production slightly increases [2]. These homogeneous base catalysts are harmful, required in more than the stoichiometric amount and have high operating cost. Solid base catalyst seems to be a promising candidate for replacing a homogeneous process for solving the above said problems. Sr based catalysts are important due to high basicity and insolubility in organic solvents, vegetable oil, FAMES (fatty acid methyl ester) [3]. In this work strontium carbonate deposited fly ash catalyst has been reported as reusable solid base catalyst for transesterification reaction. Fly ash not only provides uniform dispersion of the strontium salt but also makes strong interaction with deposited species.

\section{Experimental}

Fly ash was collected from Jamshedpur Thermal Power Station, Jamshedpur (Jharkhand). All chemicals $\operatorname{Sr}\left(\mathrm{CO}_{3}\right)_{2}(98 \%)$, methanol were purchased from Sigma Aldrich and soybean from Alfa Aser. Mechanically activated fly ash (30h at 250 rotation/ minute speed) was thermally activated at $800{ }^{\circ} \mathrm{C}$ for $3 \mathrm{~h}$ to form thermally activated fly ash (TFA) consequently $\mathrm{C}, \mathrm{S}$, moisture and other impurities also get removed [4]. An aqueous solution of strontium carbonate (for $15 \mathrm{wt} \%$ loading) was added into $10 \mathrm{~g}$ TFA at constant stirring. Resultant slurry was aged for $1 \mathrm{~h}$ then filtered and washed with double distilled water until $\mathrm{pH}$ 7 to remove leached compounds, air dried at $110{ }^{\circ} \mathrm{C}$ for $24 \mathrm{~h}$ and calcined at $430{ }^{\circ} \mathrm{C}$ for $3 \mathrm{~h}$ in a muffle furnace under static conditions to form strontium oxide loaded thermally activated fly ash (Sr/TFA). Pure SrO was formed by calcination of strontium carbonate at $430{ }^{\circ} \mathrm{C}$ for $3 \mathrm{~h}$ in muffle furnace.

Specific surface area and average pore diameter of samples are determined by $\mathrm{N} 2$ adsorption-desorption, done by using Thermo ScientificTM Surfer surface area analyzer. The FTIR spectra of the synthesized materials were recorded using IR Tensor 27 Brucker in DRS (Diffuse Reflectance Spectroscopy) by mixing the sample with $\mathrm{KBr}$ in 1:20 weight ratio in the range $550-4000 \mathrm{~cm}-1$ with a resolution of $4 \mathrm{~cm}-1$. The detailed imaging information about the morphology and surface texture of the samples were provided by SEM (Model-JEOL-JSM 5600).

\section{Results and Discussion}

Specific surface area of TFA and Sr/TFA are 28.47 and 23.54 $\left(\mathrm{m}^{2} / \mathrm{g}\right)$ respectively. FTIR spectra of TFA and Sr/TFA show a broad band between $3000-3600 \mathrm{~cm}^{-1}$, which is attributed to $-\mathrm{O}-\mathrm{H}$ 
stretching vibration of surface silanol groups (Si-OH), [5]. A peak centered at $1608-1617 \mathrm{~cm}^{-1}$, present in all samples is assigned to bending mode $(\delta o-H)$ of water molecule (Figure 1a) [6]. A small peak around $2830 \mathrm{~cm}^{-1}$ is assigned to $-\mathrm{C}-\mathrm{H}$ stretching vibration of organic contaminants present in TFA [7]. Peaks at 1986 and $1872 \mathrm{~cm}^{-1}$ are assigned to $\mathrm{SiO}_{2}$ as possible quartz [8]. Peaks centered at 1521 and $1681 \mathrm{~cm}^{-1}$ are due to $\left(\mathrm{CO}_{3}\right)_{2}-$ stretching vibration, visible in both spectra [7,9].A broad band between $1103-1168 \mathrm{~cm}^{-1}$ is attributed to Si-O-Si asymmetric stretching vibration [7]. A peak at approx $\sim 600 \mathrm{~cm}^{-1}$ is attributed to Si-O-Al stretching vibration [10]. FTIR spectrum of Sr/TFA (Figure 1b) shows the broader and much intense band in the region of 3000$3600 \mathrm{~cm}-1$ as compared to TFA. The increased intensity could be assigned to generation of Si-OH groups as well as to $\mathrm{Si}-\mathrm{O}-\mathrm{Sr}$ $\mathrm{OH}$ groups during the chemical activation while $\mathrm{H}$ - bonding is responsible for the broadness of the band between these groups. There is also possibility of $\mathrm{SrO}, \mathrm{Sr}(\mathrm{OH})_{2}$ and $\mathrm{SrCO}_{3}$ formation on TFA surface [11]. Some of the basic sites generated by SrO, would be due to the presence of $\mathrm{Sr}^{2+}{ }_{-} \mathrm{O}^{2-}$ ion pairs in different coordination environments [12].

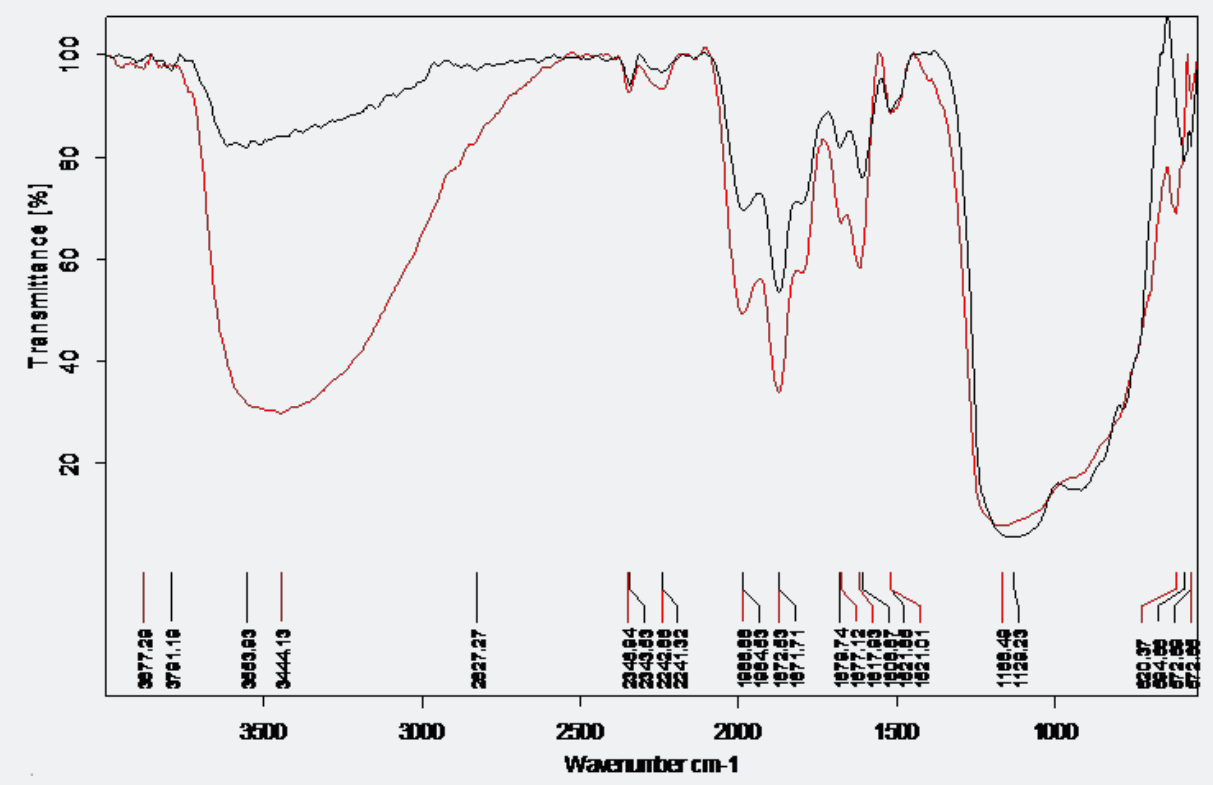

Figure 1: FTIR spectra of (a) TFA and (b) Sr/TFA.

It is observed from Figure $2 \mathrm{a}$ that fly ash mainly consist of spherical particles with smooth outer surfaces and irregularly shaped unburned carbon particles. The smooth alumina silicate spherical particles, also known as cenospheres, are formed as a result of thermo chemical transformations of mineral particles during coal combustion process, where the minerals melt to form small droplets, which upon sudden cooling and action of surface tension forces adopt the spherical shape [13]. Shiny clumps of strontium oxide on TFA surface (Figure 2b) confirm effective chemical activation, Catalytic activities of different catalytic materials were measured by transesterification reaction of soybean oil (Triglyceride) with methanol (Scheme 1). In this study refined soybean was used as a feedstock for transesterification with methanol, which was operated in $250 \mathrm{ml}$ round bottom flask on a magnetic stirrer with water cool condenser. The reaction was carried out for time ranging from $30-120 \mathrm{~min}$ at temperature $45^{\circ} \mathrm{C}$ and $65{ }^{\circ} \mathrm{C}$ maintaining $\mathrm{MeOH}$ : oil ratio $12: 1$ and substrate to catalyst weight ratio $2.7: 1$.

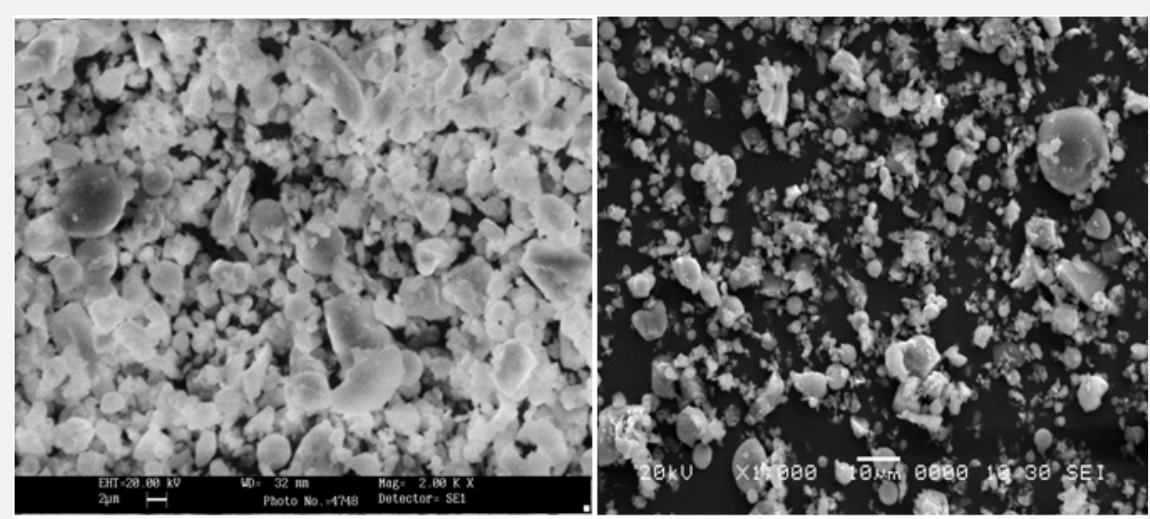

Figure 2: SEM micrographs of (a) TFA and (b) Sr/TFA. 


\section{Recent Advances in Petrochemical Science}

The conversion yield of biodiesel with pure $\mathrm{SrO}$ catalyst was about $80 \%$ at $65{ }^{\circ} \mathrm{C}$ in reaction time 135 minutes. On extending the reaction time the conversion yield decreases due to reverse reaction (Figure 3). Transesterification reaction of vegetable oils with alcohol might be in reverse direction, therefore, catalyst not only catalyze the transesterification in forward direction but also catalyze in reverse direction, which accelerated with the formation of FAMEs (Biodiesel) and glycerol [14]. Moreover Free fatty acid formed due to the reverse reaction reacts with Sr2+ ions to form soap, which decrease the yield of biodiesel with increasing reaction time.

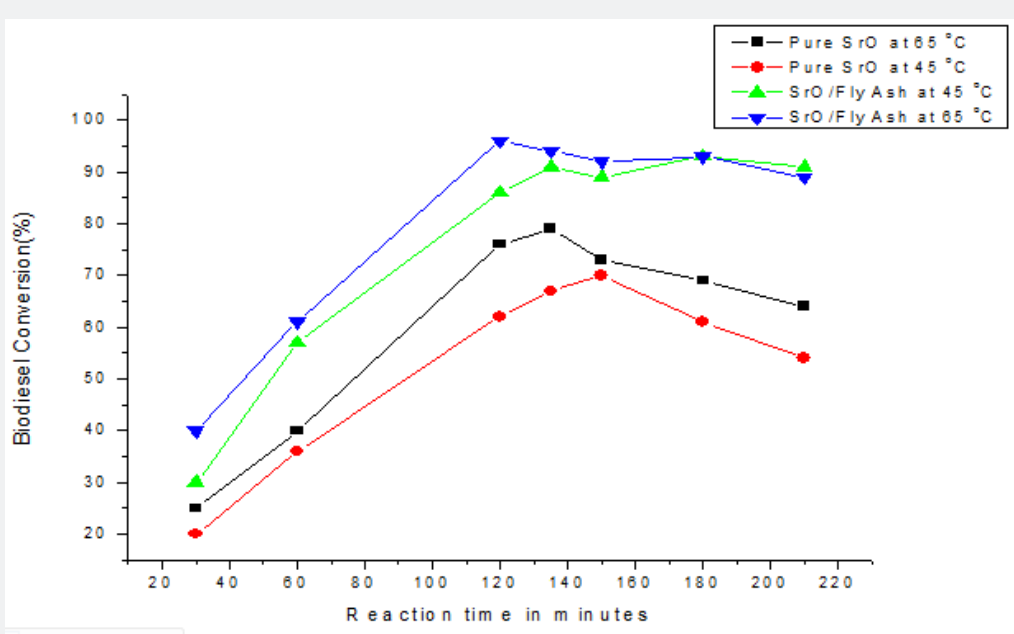

Figure 3: Effect of temperature on the efficiency of pure $\mathrm{SrO}$ and SrO/TFA catalyzed transesterification reaction.

In using $\mathrm{Sr} / \mathrm{TFA}$ catalyst the maximum yield of biodiesel conversion was obtained $86 \%$ at $65{ }^{\circ} \mathrm{C}$ (methanol to oil ratio 12:1 and substrate to catalyst ratio $2.7: 1$ ) in 121 minutes. The $\mathrm{Sr} /$ TFA catalyst was reused upto 3 reaction cycles under the same reaction conditions after washing with acetone, drying at $110{ }^{\circ} \mathrm{C}$ for $12 \mathrm{~h}$ and thermally activation at $430{ }^{\circ} \mathrm{C}$ for $2 \mathrm{~h}$. At the end of reaction resulting mixture was transferred in separating funnel and aged for $6 \mathrm{hrs}$, two layers were appeared in which upper layer was FAMEs and bottom layer was glycerol which is by product of the reaction, both layers were collected separately.

FAMEs till now have some amount of glycerol and un reacted methanol. Removal of excessive methanol was done using rotatory evaporator, subsequently, obtained FAMEs washed three times with hot water to remove remaining glycerol. Hence pure FAMEs is obtained. The properties of the prepared biodiesel at the optimal process conditions have been found to similar with the ASTM (D6751) standards [15].

\section{Conclusion}

In summary, we have synthesized the efficient, reusable strontium carbonate activated fly ash catalyst for transesterification reaction. The better conversion $\%$ in comparison to pure $\mathrm{SrO}$ enable competitive use of fly ash based catalyst in bulk production of biodiesel thus reducing cost of production. The salient features of this protocol are reusability, cost effectiveness, eco-friendly nature, and conventional reaction condition. This investigation brings into light the structural aspects of a novel fly ash supported solid base catalyst for transesterification reaction.

\section{Acknowledgement}

SEM characterizations were performed at UGC-DAE Consortium for Scientific Research, Indore. The authors are thankful to Dr DM Phase and Er VK Ahiray for SEM analysis. BET analysis was done at University of Pune, Pune. Dr. Sakshi Kabra from Department of Pure \& Applied Chemistry, University of Kota, Kota, Rajasthan helped in analytical study.

\section{References}

1. Jain D, Khatri C, Rani A (2011) Synthesis and characterization of novel solid base catalyst from fly ash. Fuel 90(6): 2083-2088.

2. Lotero E, Liu Y, Lopez DE, Suwannakarn K, Bruce DA, et al. (2005) Synthesis of Biodiesel via Acid Catalysis. Ind Eng Chem Res 44(14): 5353-5363.

3. Tantirungrotechai J, Thepwatee S, Yoosuk B (2013) Biodiesel synthesis over Sr/MgO solid base catalyst. Fuel 106: 279-284.

4. Kordatos K, Gavela G, Ntziouni A, Pistiolas KN, Kyritsi A, et al. (2008) Synthesis of highly siliceous ZSM-5 zeolite using silica from rice husk ash. Microporous Mesoporous Mater 115(1-2):189-196.

5. Jain D, Rani A (2011) MgO enriched coal fly ash as highly active heterogeneous base catalyst for claisen-schmidt condensation reaction. Am Chem Sci J 1(2): 37-49.

6. Katara S, Kabra S, Sharma A, Hada R, Rani A, et al. (2013) Surface modification of fly ash by thermal activation : A DR / FTIR Study. Int Res J Pure Appl Chem 3 (4): 299-307.

7. Saikia BJ, Parthasarathy G, Sarmah NC, Baruah GD (2008) Fouriertransform infrared spectroscopic characterization of naturally occurring glassy fulgurites. Indian Acad Sci 31(2): 155-158. 
8. Sugama T, Ecker L, Butcher T (2010) Carbonation of rock minerals by supercritical carbon dioxide at $250{ }^{\circ} \mathrm{C}$. Energy Science \& Technology Department, Brookhaven National Laboratory, Upton, NY 11973-5000, USA, pp. 1-23.

9. Handa H, Baba T, Sugisawa H, Ono Y (1998) Highly efficient selfcondensation of benzaldehyde to benzyl benzoate over KF-loaded alumina. J Mol Catal A Chem 134(1-3): 171-177.

10. Hurwitz MEGFI, Aranda DV (2008) High Temperature Aerogels in the $\mathrm{Al}_{2} \mathrm{O}_{3}-\mathrm{SiO}_{2}$ system. American Chemical Society $236^{\text {th }}$ National Meeting Philadelphia, PA, USA.

11. Dias APS, Bernardo J, Felizardo P, Correia MJN (2012) Biodiesel production by soybean oil methanolysis over $\mathrm{SrO} / \mathrm{MgO}$ catalysts. Fuel Process Technol 102: 146-155.
12. Yang Z, Xie W (2007) Soybean oil transesterification over zinc oxide modified with alkali earth metals. Fuel Process Technol 88(6): 631638.

13. Nyale SM, Babajide 00, Birch GD, Böke N, Petrik LF, et al. (2013) Synthesis and characterization of coal fly ash-based foamed geopolymer. Procedia Environ Sci 18: 722-730.

14. Karmee SK, Mahesh P, Ravi R, Chadha A (2004) Kinetic study of the base catalyzed transesterification of monoglycerides from pongamia oil. J Am Oil Chem Soc 81(5): 425-430.

15. Rashtizadeh E, Farzaneh F, Talebpour Z (2014) Synthesis and characterization of Sr3Al206 nano composite as catalyst for biodiesel production. Bioresour Technol 154: 32-37.

\begin{tabular}{|l|}
\hline \multicolumn{1}{|c|}{ Your next submission with Juniper Publishers } \\
will reach you the below assets \\
- Quality Editorial service \\
- Swift Peer Review \\
- Reprints availability \\
- E-prints Service \\
- Manuscript Podcast for convenient understanding \\
- Global attainment for your research \\
- Manuscript accessibility in different formats \\
( Pdf, E-pub, Full Text, Audio) \\
- Unceasing customer service \\
Track the below URL for one-step submission \\
https://juniperpublishers.com/online-submission.php \\
\hline
\end{tabular}

